\title{
Characterization of $\mathrm{Li}_{4} \mathrm{TiO}_{4}$ tritium breeder by a first-principles calculation and an experimental approach
}

\author{
Juemin Yan ${ }^{\mathrm{a}, \mathrm{b}}$, Nanlin $\mathrm{He}^{\mathrm{c}}$, Xiaojun $\mathrm{Chen}^{\mathrm{b}}$, Chengjian Xiao ${ }^{\mathrm{b}}$, LinJie Zhao ${ }^{\mathrm{b}}$, Tao \\ $\mathrm{Gao}^{\mathrm{a}, *}$ \\ ${ }^{a}$ Institute of Atomic and Molecular Physics, Sichuan University, Chengdu 610065, P.R. China \\ ${ }^{b}$ Institute of Nuclear Physics and Chemistry, China Academy of Engineering Physics, Mianyang 621903,
} P.R. China

${ }^{c}$ Basic Department, Police officer college of Armed Police Force, Chengdu 610065, P.R. China
*Corresponding Author Information: E-mail address: emailyjm@163.com

\begin{abstract}
Tetralithium titanium $\left(\mathrm{Li}_{4} \mathrm{TiO}_{4}\right)$ compound is a tritium breeder material that deserves serious consideration for fusion reactor blanket concept because of its high lithium density. In the current research, an experimental investigation was used for the first time to verify the calculated simulation results. First, the lattice parameters, energy band structures and thermodynamic properties of $\mathrm{Li}_{4} \mathrm{TiO}_{4}$ are investigated by means of first-principles density functional theory. Then, the $\mathrm{Li}_{4} \mathrm{TiO}_{4}$ powder was synthesized via a solid-state reaction. Subsequently, the samples were systematically characterized using various measurement techniques. The products of ultraviolet diffuse reflection spectrum, Raman spectroscopy and laser thermal conductivity are consistent with the theoretical calculations.
\end{abstract}

Keywords: Tritium breeder material, $\mathrm{Li}_{4} \mathrm{TiO}_{4}$, First-principles, Density functional, Solid-state reaction, 


\section{Introduction}

Controlled fusion energy is the most significant solution for contributing to energy betterment without polluting the environment [1,2]. Tritium breeder materials have played a pivotal role in the test blanket module of deuterium-tritium fusion reactor due to the tritium production from breeder materials at the time of the reaction process [3-5]. Lithium-based ceramics are one of best prospects for tritium breeding materials because of their high lithium density, competent tritium release performance, commendable thermal conductivity, favorable chemical stability, prominent anti-radiation capability and compatibility with other blanket modules [6-8]. Among these properties, lithium density has a direct bearing on the tritium breeding ratio, in these materials, the value of lithium density is as large as possible [9]. Over the last several decades, immense amounts of research have been conducted on tritium breeding materials both here and abroad. Moreover, an impressive body of literature indicates that $\mathrm{Li}_{2} \mathrm{O}, \mathrm{Li}_{2} \mathrm{TiO}_{3}, \gamma-\mathrm{LiAlO}_{2}, \mathrm{LiSiO}_{3}$ and $\mathrm{Li}_{4} \mathrm{SiO}_{4}$ have been recommended for tritium breeding materials in the light of various attractive characteristics [10-17]. At the same time, scientific researchers are constantly developing new candidate tritium breeder materials.

In recent years, tetralithium titanium $\left(\mathrm{Li}_{4} \mathrm{TiO}_{4}\right)$ ceramic has attracted much public attention due to their high lithium density and hidden potential as tritium breeder materials [39]. Furthermore, $\mathrm{Li}_{4} \mathrm{TiO}_{4}$ has many other uses in thermal batteries and carbon dioxide adsorbents. Researchers in the $\mathrm{Li}_{4} \mathrm{TiO}_{4}$ field have made some developments. To enhance the lithium density of $\mathrm{Li}_{2} \mathrm{TiO}_{3}$ ceramic breeder material, advanced lithium titanate $\left(\mathrm{Li}_{2} \mathrm{TiO}_{3}\right.$ added with $\left.\mathrm{Li}_{4} \mathrm{TiO}_{4}\right)$ has been meticulously investigated using solid-state reactions $[18,19]$. There is also some evidence suggesting that the $\mathrm{Li}_{4} \mathrm{TiO}_{4}$ to high $\mathrm{Li}_{2} \mathrm{TiO}_{3}$ solution and liquid reaction increases with the addition of $\mathrm{Li}_{2} \mathrm{O}$ at high temperature [20,21]. Furthermore, due to its advanced $\mathrm{CO}_{2}$ chemisorption function, $\mathrm{Li}_{4} \mathrm{TiO}_{4}$ can be used as a carbon dioxide adsorbent to reduce planetary warming [22-26].

At present, an investigation involving theoretical calculations and experimental research was carried out to obtain a good and comprehensive understanding of the microscopic properties $\mathrm{Li}_{4} \mathrm{TiO}_{4}$ ceramic. In addition, the formation of $\mathrm{Li}_{4} \mathrm{TiO}_{4}$ occurred as follows:

$$
4 \mathrm{LiOH} \cdot \mathrm{H}_{2} \mathrm{O}+\mathrm{TiO}_{2} \rightarrow \mathrm{Li}_{4} \mathrm{TiO}_{4}+6 \mathrm{H}_{2} \mathrm{O}
$$




\section{Computational and Experimental Methods}

\subsection{Computational details}

The calculation method presented in this paper is accomplished with the Vienna $\mathrm{Ab}$ initio Simulation Package (VASP) [27-29], which is based on first-principles density functional theory [30]. The projector augment wave (PAW) pseudopotential is used to explain the mutual effect of ions and electrons [31,32]. The Perdew-Wang scheme (PW91) exchange-correlation function of the generalized gradient approximation (GGA) is implemented for electron exchange correlation [33]. The radial cutoffs of the PAW potentials of $\mathrm{Li}, \mathrm{Ti}$, and $\mathrm{O}$ are 2.23, 2.81 and $1.53 \AA$, respectively. The valence electrons are comprised of the $\mathrm{s}$ and $\mathrm{p}$ orbit of $\mathrm{Li}$ and $\mathrm{O}$ atoms, and the $\mathrm{d}$ and $\mathrm{s}$ orbit of $\mathrm{Ti}$ atom. The atoms are overall allowed in the cell to relax in the optimizations. Plane-wave basis sets are employed with a kinetic energy cutoff of $530 \mathrm{eV}$ and an augmentation charge cutoff of $615.3 \mathrm{eV}$. The total energy was converged within $10^{-6} \mathrm{eV}$ to eliminate the errors in the calculation of the forces. The Brillouin zone quadrature is performed on gamma point shifted Monkhorst-Pack meshes, where the k-point grid is converged to less than $1 \mathrm{meV}$ in terms of the ground state energy, which complies with a spacing of about $0.028 \AA^{-1}$ along the axes of the reciprocal unit cells. The corresponding k-point sets we used in our calculations were $6 \times 6 \times 6$. Lattice constants and internal coordinates were obtained from the optimized structure. Accordingly, the electronic energy band structure was acquired along the high-symmetry point in the Brillouin zone. The phonon spectrum and thermodynamic properties were calculated using the PHONOPY software package [34-36]. Phonon calculation was performed from a $2 \times 2 \times 2$ supercell, and then the infrared (IR) with Raman-active modes was obtained from longitudinal optical-transverse optical (LO-TO) splitting [37]. Finally, the specific heat $\left(\mathrm{C}_{\mathrm{v}}\right)$ value as a function of temperature was obtained according to the phonon density of states.

\subsection{Experimental details}

The solid compound $\mathrm{Li}_{4} \mathrm{TiO}_{4}$ was synthesized by a solid-state reaction [3]. The starting materials were $\mathrm{LiOH} \cdot \mathrm{H}_{2} \mathrm{O}$ ( Aladdin chemistry Co. Ltd., 99.0\% ), and $\mathrm{TiO}_{2}$ ( Alfa Aesar chemicals Co. Ltd., 99.8\% ). Subsequently, the preparation process is described briefly in the following text. First, a certain amount of mixture was blended in a ceramic jar through wet planetary ball milling for 2.5 hours (using ethanol and $\mathrm{SiO} 2$ balls as the accessory factor). Second, the mixture was placed in an alumina crucible and sintered at temperatures ranging from $800{ }^{\circ} \mathrm{C}$ to $1000{ }^{\circ} \mathrm{C}$ for 9 hours in 
different atmospheres. Then, the sintered sample was pressed at $12 \mathrm{MPa}$ into pellets (13 $\mathrm{mm}$ in diameter and $0.3 \mathrm{~mm}$ thick) and sintered at $900{ }^{\circ} \mathrm{C}$ for 10 hours. The thermal conductivity of the sintered sample was measured by a laser flash diffusivity apparatus. The composition and phase structure of the sample were characterized by X-ray diffraction (XRD), the energy band properties of the sample were characterized by ultraviolet spectrophotometer and the Raman activity was characterized by Raman spectrometry.

\section{Result and Discussion}

\subsection{Optimizing lattice constant and $\mathrm{Li}_{4} \mathrm{TiO}_{4}$ synthesis}

The optimized lattice parameters and experimental data are listed in Table 1 and the deviation is less than $3.1 \%$. The $\mathrm{Li}_{4} \mathrm{TiO}_{4}$ ceramic powder was synthesized through a solid-state reaction. The powders were sintered at $800,900,1000{ }^{\circ} \mathrm{C}$ for 9 hours. Then the XRD patterns of the samples obtained at different temperature were compared (Fig. 1). Research has shown that $800{ }^{\circ} \mathrm{C}$ is the appropriate temperature for the synthesis of these sample. Next, the effect of the reaction atmosphere on sample synthesis was studied. In Fig. 2, the XRD patterns of the samples obtained at different reaction atmospheres were compared. The experimental analysis of the test samples showed that $\mathrm{Li}_{2} \mathrm{TiO}_{3}$ powder eventually formed in an argon atmosphere. For further investigation, the $\mathrm{Li}_{4} \mathrm{TiO}_{4}$ ceramic powder was sintered at $800{ }^{\circ} \mathrm{C}$ for 9 hours and the corresponding XRD patterns are provided in Fig. 3.

\subsection{Band gap calculation and experimental measurement}

The calculated band structure of $\mathrm{Li}_{4} \mathrm{TiO}_{4}$ is presented in Fig. 4. The Fermi energy level may be used as a reference relative to zero. $\mathrm{Li}_{4} \mathrm{TiO}_{4}$ has an indirect band gap because the conduction band minimum with the valence band maximum live at different high-symmetry points, with the valence band maximum remaining below the Fermi energy level. At the same time, the actual calculation of indirect band gap is $4.21 \mathrm{eV}$. Based on the Reference [38], the band gap values computed using DFT are usually smaller than the experimental measurements. Therefore, the width of the band gap of the synthetic $\mathrm{Li}_{4} \mathrm{TiO}_{4}$ ceramic powder was determined experimentally using ultraviolet diffuse reflection spectroscopy.

Photon energy must satisfy the following condition in intrinsic absorption:

$$
\hbar \omega \geq E_{g}
$$


where, $E_{g}$ and $\hbar \omega$ are the forbidden band and photon energy, respectively. Because the photon energy is greater than or equal to the forbidden band energy, $\omega=\omega_{0}$, the intrinsic absorption edge, makes the photon energy equal to the forbidden band. We can verify the forbidden band value by experimentally measuring the intrinsic absorption edge. The absorbance as a function of photon energy is described by the following formula:

$$
(A E)^{m}=B\left(E-E_{g}\right)
$$

Where, $A, B$ and $m$ are absorbance, energy constant and electron transition coefficient, respectively. The reflectivity of the powder sample to ultraviolet light was directly measured (mode UV-3600, wavelength from 200 to $1100 \mathrm{~nm}$ ). Because $\mathrm{Li}_{4} \mathrm{TiO}_{4}$ has an indirect band, $(A E)^{2}$ is a fundamental aspect to include in visualizations of $E$ (Fig. 5). In the figure, the intersection of the tangent and abscissa represents the energy band value. Meanwhile, the value of the energy band is $4.39 \mathrm{eV}$, which is slightly larger than the DFT calculated ones and band and therefore verifies the literature.

\subsection{Phonon and Raman spectrum}

The calculated phonon dispersion curves of $\mathrm{Li}_{4} \mathrm{TiO}_{4}$ are shown in Fig. 6. There are 18 atoms in the $\mathrm{Li}_{4} \mathrm{TiO}_{4}$ unit cell and, consequently, there are 54 branches in its system. According to group theory, the irreducible representations of $\mathrm{Li}_{4} \mathrm{TiO}_{4}$ in the Brillouin zone are:

$$
\begin{gathered}
\Gamma_{a c o}=B_{1 u}+B_{2 u}+B_{3 u} \\
\Gamma_{o p t}=8 A_{g}+8 B_{1 g}+5 B_{2 g}+6 B_{3 g}+6 B_{1 u}+8 B_{2 u}+6 B_{3 u}+4 A_{u}
\end{gathered}
$$

where $\Gamma_{a c o}$ denotes the three acoustic modes: $B_{1 u}, B_{2 u}$ and $B_{3 u} . \Gamma_{o p t}$ denotes the optical modes. $A_{g}, B_{1 g}, B_{2 g}, B_{3 g}, B_{1 u}, B_{2 u}$ and $B_{3 u}$ are active modes, while $A_{u}$ is inactive. The letters $u$ and $g$ represent IR-active modes and Raman-active modes, respectively. For $\mathrm{Li}_{4} \mathrm{TiO}_{4}$, there are 27 Raman-active modes and 20 IR-active modes. Longitudinal optical-transverse optical (LO-TO) splitting is shown in Fig. 6.

Next, the $\mathrm{Li}_{4} \mathrm{TiO}_{4}$ powder sample were characterized by laser Raman spectroscopy at a wavelength of $532 \mathrm{~nm}$. These characterization results are shown in Fig. 7. Due to the sample purity, the minority sample reacts with water and $\mathrm{CO}_{2}$ to produce $\mathrm{Li}_{2} \mathrm{CO}_{3}$. A higher frequency than $1000 \mathrm{~cm}^{-1}$ was observed in Raman spectroscopy, probably because of the vibration of the $\mathrm{CO}_{3}^{2-}$ vibration. Table 2 lists the calculated and experimental Raman values. Part of the peaks were not visible, 
which might be attributed to the weak vibration from the atoms. As seen in the table, the calculated values are essentially consistent with the experimental values.

\subsection{Thermal properties}

For application in the international thermonuclear experimental reactor (ITER) test blanket module, excluding tritium production, the solid tritium breeding material should have distinguished energy transformation performance. Therefore, it is very important for such solid breeding materials to have prominent thermal conductivity. The thermal conductivity was obtained from the thermal diffusion coefficient and specific heat by means of:

$$
\lambda=\alpha \cdot \rho \cdot C_{p}
$$

where $\lambda, \alpha, \rho$ and $C_{p}$ are thermal conductivity, thermal diffusion coefficient, density and specific heat, respectively.

On the basis of phonon dynamical properties, the constant volume specific heat, $\mathrm{C}_{\mathrm{v}}$, of $\mathrm{Li}_{4} \mathrm{TiO}_{4}$ was calculated using the density functional perturbation theory (DFPT). According to the harmonic approximation, the value of $\mathrm{C}_{\mathrm{v}}$ can be written as:

$$
C_{v}=3 n N k_{B} \int_{0}^{\omega_{L}}\left(\frac{\hbar \omega}{2 k_{B} T}\right)^{2} \csc h^{2}\left(\frac{\hbar \omega}{2 k_{B} T}\right) g(\omega) d \omega
$$

Where, $\hbar, k_{B}, \omega$ and $\omega_{L}$ are the Planck constant, Boltzman constant, phonon frequency and largest frequency, respectively. Furthermore, $n$ denotes the quantity of atoms in each unit cell, $N$ denotes the number of unit cell, and $g(\omega)$ is the normalized phonon density of states. The relationship between $\mathrm{C}_{\mathrm{v}}$ and the specific heat at constant pressure $\left(\mathrm{C}_{\mathrm{p}}\right)$ is defined as follows:

$$
C_{p}(T, p)=-T \frac{\partial^{2} G(T, p)}{\partial T^{2}}=\left.T \frac{\partial V(T, p) \partial S(T ; V)}{\partial T \quad \partial V}\right|_{V=V(T, p)}+C_{v}[T, V(T, p)]
$$

Where $V$ is the volume, $p$ is the pressure and $G(T, p)$ is the Gibbs free energy, which is obtained via the following formula:

$$
G(T, p)=\min \left[U(V)+F_{\text {phonon }}(T ; V+p V)\right]
$$

where $U(V)$ is the total energy of the electronic structure at a constant volume. $\mathrm{C}_{\mathrm{p}}$ was obtained from the quasi-harmonic approximation (QHA). For the QHA calculation, the force constants are determined at 13 vol points by the optimized 
lattice parameter. The heat capacities $\left(\mathrm{C}_{\mathrm{v}}\right.$ and $\left.\mathrm{C}_{\mathrm{p}}\right)$ as function of temperature are presented in Fig. 8. Comparing the two curves in the figure, both $\mathrm{C}_{\mathrm{v}}$ and $\mathrm{C}_{\mathrm{p}}$ increase with increasing temperature and are similar at low temperatures. As the temperature rises, $C_{p}$ maintains a positive slope while $C_{v}$ tends to be horizontal.

Subsequently, the measurement details and values are clearly described in the following paragraph. First, because graphite is a highly efficient electric conductor, graphite is evenly coated with a thin layer of graphite on the surface of compressed ultrathin samples. It is important to ensure a consistent ratio of infrared emission and light absorption to the testing and standard samples. Then, the specific heat of the samples was tested by a laser flash diffusivity apparatus. As shown in Fig. 9, the specific heat increased with increasing temperature. Nevertheless, the thermal conductivity increased with decreasing temperature, as shown in Fig. 10. The theoretically calculated value agrees well with the experimental data.

\section{Conclusions}

This paper has investigated scientifically $\mathrm{Li}_{4} \mathrm{TiO}_{4}$, First the structure, dynamical and thermodynamic properties of $\mathrm{Li}_{4} \mathrm{TiO}_{4}$ were successfully studied via first-principles DFT. The $\mathrm{Li}_{4} \mathrm{TiO}_{4}$ powder was successfully synthesized through a solid-state reaction under stable conditions. Subsequently, the samples were systematically characterized by various measurement techniques.

As follows, the deviation between the optimized lattice parameters and the experimental data is less than $3.1 \%$. The band gap value $(4.21 \mathrm{eV})$ computed by DFT is usually smaller than the experimental measurement $(4.39 \mathrm{eV})$. The result is therefore consistent with the literature. Subsequently, the phonon dispersion curves of $\mathrm{Li}_{4} \mathrm{TiO}_{4}$ and the Raman-active modes were obtained. The $\mathrm{Li}_{4} \mathrm{TiO}_{4}$ powder sample was characterized by laser Raman spectroscopy and the measurements greatly corresponded to the calculated values. Finally, the specific heat of $\mathrm{Li}_{4} \mathrm{TiO}_{4}$ was accurately measured from the DFPT and the laser flash diffusivity apparatus, which indicated that the thermal conductivity of the samples was distinctly acquired.

Several conclusions could be drawn from the results described above. In the current research on $\mathrm{Li}_{4} \mathrm{TiO}_{4}$, experimental testing was first used to verify the calculation simulation results. Specifically, $\mathrm{Li}_{4} \mathrm{TiO}_{4}$ ceramic can be used as a suitable candidate solid tritium breeder material in fusion-fission or fusion reactor blankets. The tritium release behavior of $\mathrm{Li}_{4} \mathrm{TiO}_{4}$ ceramics is vitally important for the future research. 


\section{Acknowledgements}

This work was supported by the National Magnetic Confinement Fusion Science Program (No. 2014GB111001, No. 2014GB 125002 and No.2013GB110000).

\section{References}

[1]. Miley, G. H. Fusion energy conversion. Amer Nuclear Society 1976.

[2]. Souers, P.; Clark, S. Hydrogen properties for fusion energy. Univ of California Press 1986.

[3]. Zhu, D.; Peng, S.; Chen, X.; Gao, X.; Yang, T. Fabrication and characterization of Li3 TaO4 ceramic pebbles by wet process. J. Nucl. Mater. 2010, 396, 245-250.

[4]. Johnson, C. E. Research and development status of ceramic breeder materials. J. Nucl. Mater. 1991, 179-181, 42-46.

[5]. Giancarli, L. M.; Barabash, V.; Campbell, D. J.; Chiocchio, S.; Cordier, J.-J.; Dammann, A.; Dell'Orco, G.; Elbez-Uzan, J.; Fourneron, J.M.; Friconneau, J.P.; Gasparotto, M.; Iseli, M.; Jung, C. Y. Progress and challenges of the ITER TBM Program from the IO perspective, Fusion Eng. Des. 2016, 109, 1491-1497.

[6]. Raffray, A. R.; Akiba, M.; Chuyanov, V.; Giancarli, L.; Malang, S. Breeding blanket concepts for fusion and materials requirements. J. Nucl. Mater. 2002, 307-311, 21-30.

[7]. Konishi, S.; Enoeda, M.; Nakamichi, M.; Hoshino, T.; Ying, A.; Sharafat, S.; Smolentsev, S. Funstional materials for breeding blankets-status and developments. Nucl. Fusion. 2017, 57, 092014.

[8]. Kresse, G.; Hafner, J. Ab initio molecular dynamics for liquid metals. Phys. Rev. B 1993, 47, 558-561.

[9]. Johnson, C. E.; Noda, K.; Roux. N. J. Nucl. Mater. 1998, 258-263, 140-148.

[10].Wen, Zhao.; Gu, Zhong.; Xu, Xiao.; Zhu, Xiu. Research on the preparation, electrical and mechanical properties of $\gamma-\mathrm{LiAlO}_{2}$ ceramics. J. Nucl. Mater. 2004, 329-333, 1283-1286.

[11].Tsuchiya, K.; Kawamura, H.; Fuchinoue, K.; Sawada, H.; Watarumi, K. Fabrication development and preliminary characterization of $\mathrm{Li}_{2} \mathrm{TiO}_{3}$ pebbles by 
wet process. J. Nucl. Mater. 1998, 258-263, 1985-1990.

[12].WERLE, H.; BREITUNG, W.; BRIEC, M.; CLEMMER, R. G.; ELBEL, H.; HAFNER, H. E.; MASSON, M.; SCHUMACHER, G.; WEDEMEYER, H. The LISA-2 EXPERIMENT: IN-SITU TRITIUM RELEASE FROM LITHIUM ORTHOSILICATE $\left(\mathrm{L}_{4} \mathrm{SiO}_{4}\right)$. J. Nucl. Mater. 1988, 155-157, 538-543.

[13]. Donato, A. A critical review of $\mathrm{Li}_{2} \mathrm{O}$ ceramic breeder material properties correlations and data. Fusion Eng. Des. 1998, 38, 362-392.

[14].Lulewic, J. D.; Roux, N. Fabrication of $\mathrm{Li}_{2} \mathrm{TiO}_{3}$ pebbles by the extrusion -spheronisation-sintering process. J. Nucl. Mater. 2002, 307-311, 803-806.

[15].Hoshino, T.; Oikawa, F. Trial fabrication tests of advanced tritium breeder pebbles using sol-gel method. Fusion Eng. Des. 2011, 86, 2172-2175.

[16].Knitter, R.; Alm, B.; Roth, G. J. Nucl. Mater. 2007, 367-370, 1387-1392.

[17].Kolb, M. H. H.; Bruns, M.; Knitter, R. Lithium orthosilicate surfaces: Characterization and effect on tritium release. J. Nucl. Mater. 2012, 427,126-132.

[18].Hoshino, T.; Katoet, K.; Natori, Y.; Nakamura, M.; Sasaki, K.; Hayashi, K.; Terai, T.; Tatenuma, K. New synthesis method of advanced lithium titanate with $\mathrm{Li}_{4} \mathrm{TiO}_{4}$ additives for ITER-TBM. Fusion Eng. Des. 2009, 84, 956-959.

[19].Hoshino, T.; Kato, K.; Natori, Y.; Oikawa, F.; Nakano, N.; Nakamura, M.; Sasaki, K.; Suzuki, A.; Terai, T.; Tatenuma, K. Development of advanced tritium breeding material with added lithium for ITER-TBM. J. Nucl. Mater. 2011, 417, 684-687.

[20].Asano, M.; Nakagawa, H. Thermochemical study of vaporization of $\mathrm{Li}_{4} \mathrm{TiO}_{4}$ by a mass spectrometric Knudsen effusion. J. Nucl. Mater. 1988, 160, 172-177.

[21].Izquierdo, G.; West, A. R. Phase equilibria in the system $\mathrm{Li}_{2} \mathrm{O}-\mathrm{TiO}_{2}$. Mat. Res. Bull. 1980, 15, 1655-1660.

[22].Togashi, N.; Okumura, T.; Katsuyoshi, O. Synthesis and $\mathrm{CO}_{2}$ Absorption Property of $\mathrm{Li}_{4} \mathrm{TiO}_{4}$ as a Novel $\mathrm{CO}_{2}$ Absorbent. J. Ceram. Soc. Japan 2007, 115, 324-328.

[23].Dubey, B. L.; West, A. R. Preparation of the $\mathrm{Li}_{4} \mathrm{TiO}_{4}$ containing Tetrahedrally Coordinated $\mathrm{Ti}^{4+}$, Nature, Phy. Sci. 1972, 235, 155-156.

[24].Guanwardane, R. P.; Fletcher, J. G.; Dissanayake, M. A. K. L.; et al., Howie. R. 
A.; West. A. R. Crystal structure refinement of $\mathrm{Li}_{4} \mathrm{TiO}_{4}$ containning Tetrahedrally Coordinated $\mathrm{Ti}^{4+}$ and tetragonally packed oxide ions. J. Solid State Chem. 1994, $112,70-72$.

[25].Dubey, B. L.; West, A. R. Crystal chemistry of $\mathrm{Li}_{4} \mathrm{XO}_{4}$ phase: $\mathrm{X}=\mathrm{Si}, \mathrm{Ge}, \mathrm{Ti}, \mathrm{J}$. Inorg. Nucl. Chem. 1973, 35, 3713-3717.

[26].Ueda, S.; Inoue, R.; Sasaki, K.; Wakuta, K.; Ariyama, T. $\mathrm{CO}_{2}$ absorption and desorption abilities of $\mathrm{Li}_{2} \mathrm{O}-\mathrm{TiO}_{2}$ compounds. IISIJ. Int. 2011, 51, 530-537.

[27].Tian, X.; Gao, T.; Lu, C.; Shang, J.; Xiao, H. First principle study of the behavior of helium in plutonium dioxide. Eur. Phys. J. B 2013, 86, 179.

[28].He, N.; Chen, X. First principles study of ceramic materials (IVB group carbides) under ultrafast laser irradiation. Chin. Phys. B 2018, 27, 036301.

[29].Kresse, G.; Hafner, J. Ab initio molecular dynamics for liquid metals. Phys. Rev. B 1993, 47, 558-561.

[30].Yan, J.; Gao, T. First-principles calculation of structural, electronic, dynamical, and thermodynamic properties of $\mathrm{Li}_{4} \mathrm{TiO}_{4}$. Fusion Eng. Des. 2018, 129, 241-246.

[31].Blochl, P.E. Projector augmented-wave method. Phys. Rev. B 1993, 47, 558-561.

[32].Kresse, G.; Joubert, D. From ultrasoft pseudopotentials to the projector augmented-wave method. Phys. Rev. B 1999, 59, 1758-1775.

[33].Perdew, J. P.; Burke, K.; Ernzerhof, M. Generalized Gradient Approximation Made Simple. Phys. Rew. L 1996, 77, 3865-3868.

[34].Togo, A.; Oba, F.; Tanaka, I. First-principles calculations of the ferroelastic transition between rutile-type and $\mathrm{CaCl}_{2}$-type, $\mathrm{SiO}_{2}$ at high pressures. Phys, $\mathrm{Rev}$. B 2008, 78, 134106.

[35].Gajdos, M.; Hummer, K.; Kresse, G.; Furthmuller, J.; Bechstedt, F. Linear optical properties in the projector-augmented wave methodology. Phys. Rev. B 2006, 73, 045112.

[36]. Gone, X. Perturbation expansion of variational principles at arbitrary order. Phys. Rev. A 1995, 52, 1086-1095.

[37].Gone, X.; Lee, C. Dynamical matrices, Born effective charges, dielectric permittivity tensors, and interatomic force constants from density-functional perturbation theory. Phys, Rev. B 1997, 55, 10355. 
[38].Guan, Q.; Chen, X. First-principles study of the structural, electronic, dynamical, and thermodynamic properties of $\mathrm{Li}_{5} \mathrm{AlO}_{4}$. J. Nucl. Mater. 2015, 465, 170-176.

[39]. Chen, R.; Lu, T. Microstructure and phase evolution of $\mathrm{Li}_{4} \mathrm{TiO}_{4}$ ceramics pebbles prepared from a nanostructured precursor powder synthesized by hydrothermal method. J. Nucl. Mater. 2018, 508, 434-439.

\section{List of captions}

Fig. 1. XRD patterns of $\mathrm{Li}_{4} \mathrm{TiO}_{4}$ sample powders at different temperatures.

Fig. 2. XRD patterns of $\mathrm{Li}_{4} \mathrm{TiO}_{4}$ sample powders at different reaction atmospheres.

Fig. 3. XRD patterns of $\mathrm{Li}_{4} \mathrm{TiO}_{4}$ sample powders heated at $800^{\circ} \mathrm{C}$ for 9 hours.

Fig. 4. The calculated band structure of $\mathrm{Li}_{4} \mathrm{TiO}_{4}$.

Fig. 5. The measured indirect band of $\mathrm{Li}_{4} \mathrm{TiO}_{4}$.

Fig. 6. The calculated phonon dispersion curves of $\mathrm{Li}_{4} \mathrm{TiO}_{4}$.

Fig. 7. Raman spectroscopy characterization of Li4TiO4 powder samples.

Fig. 8. The heat capacities $\left(\mathrm{C}_{\mathrm{v}}\right.$ and $\left.\mathrm{C}_{\mathrm{p}}\right)$ as the function a temperature.

Fig. 9. Laser flash diffusivity test of the $\mathrm{Li}_{4} \mathrm{TiO}_{4}$ sample specific heat.

Fig.10. The thermal conductivity with decreasing temperature.

Table 1. The optimized and experimental lattice parameters of $\mathrm{Li}_{4} \mathrm{TiO}_{4}$.

Table 2. The calculated and experimental Raman values. 
Fig. 1

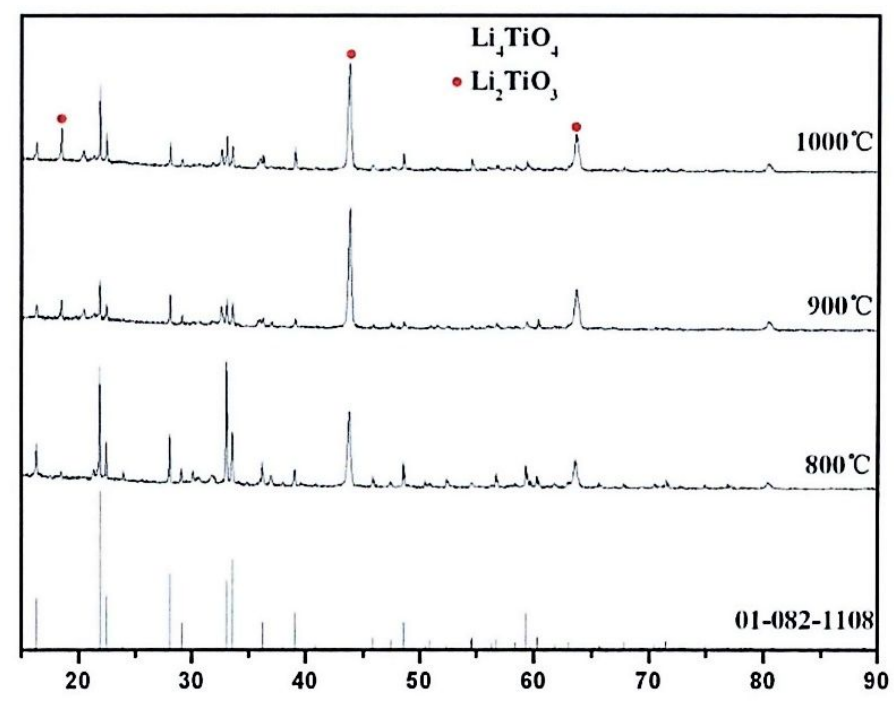


Fig. 2

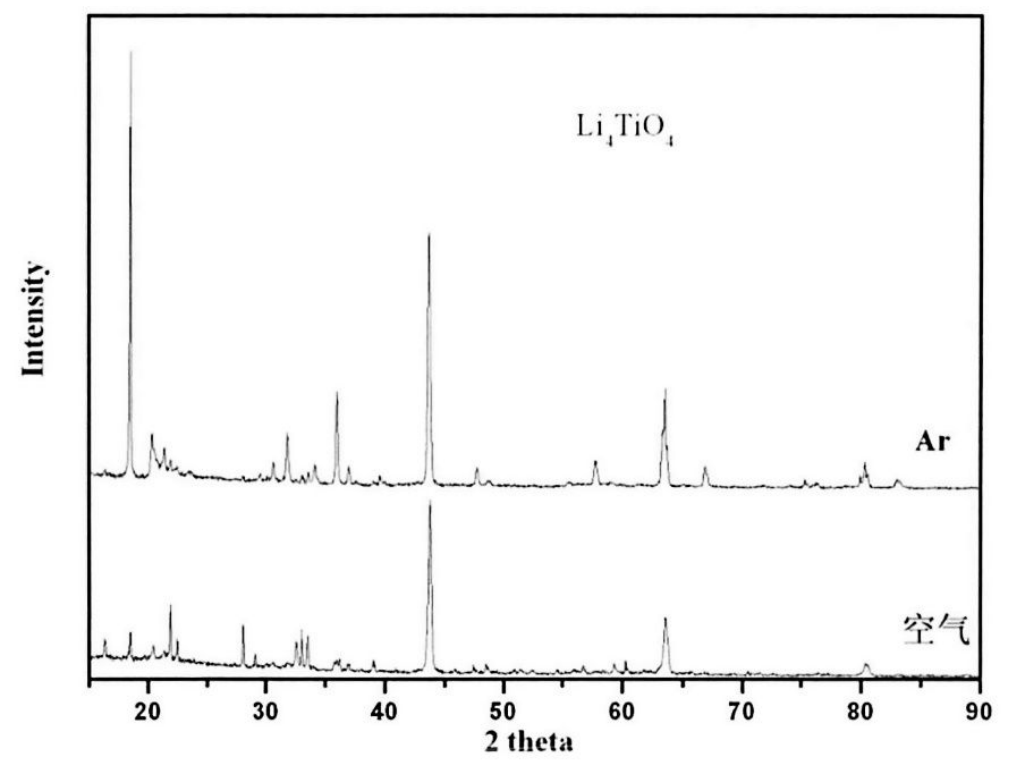


Fig. 3

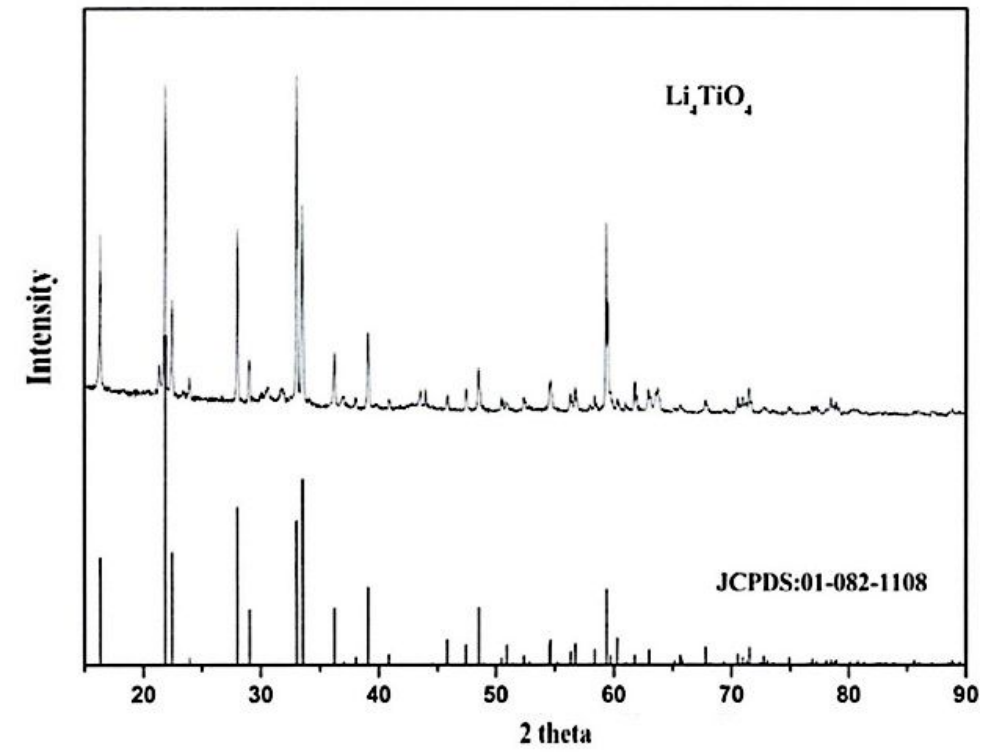


Fig. 4

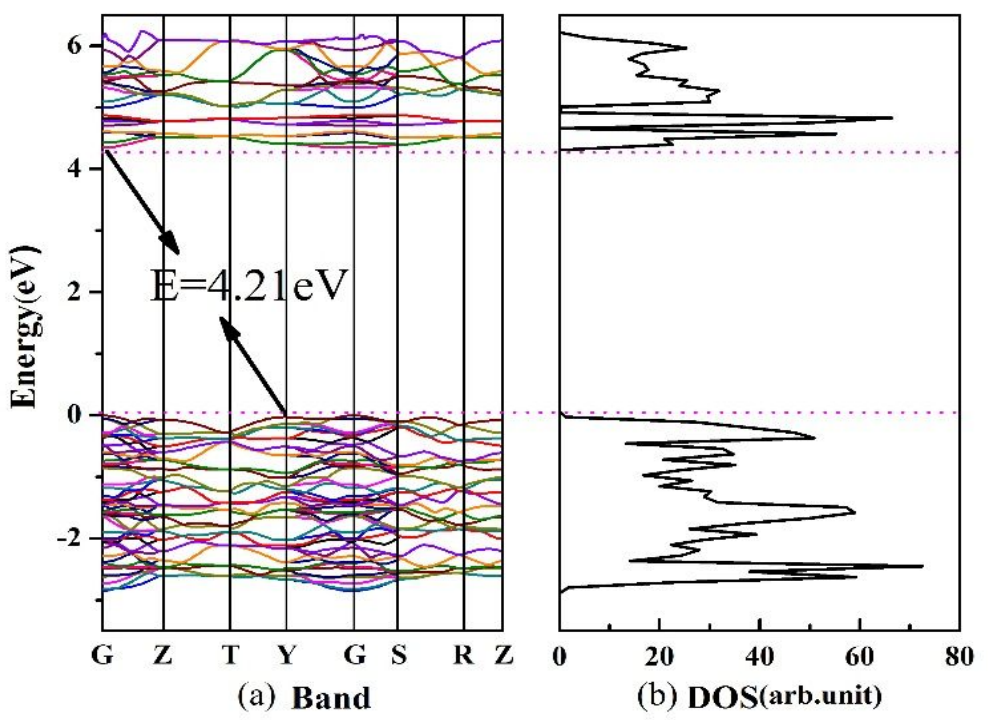


Fig. 5

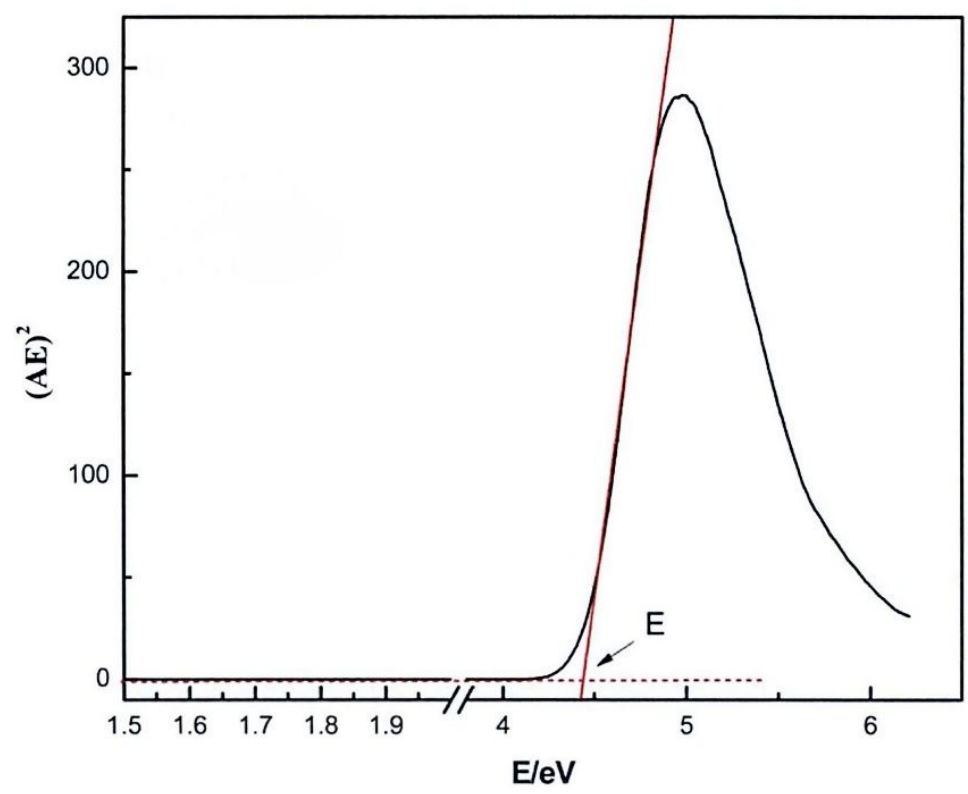


Fig. 6

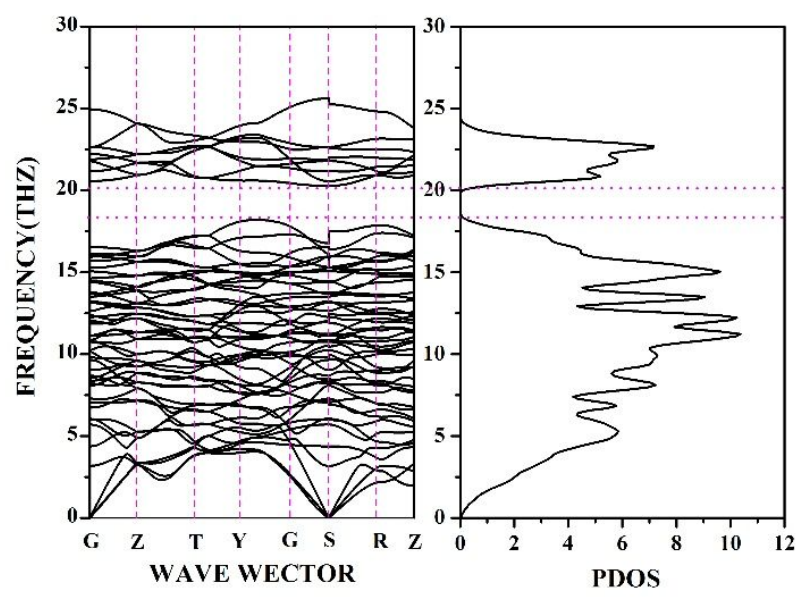


Fig. 7

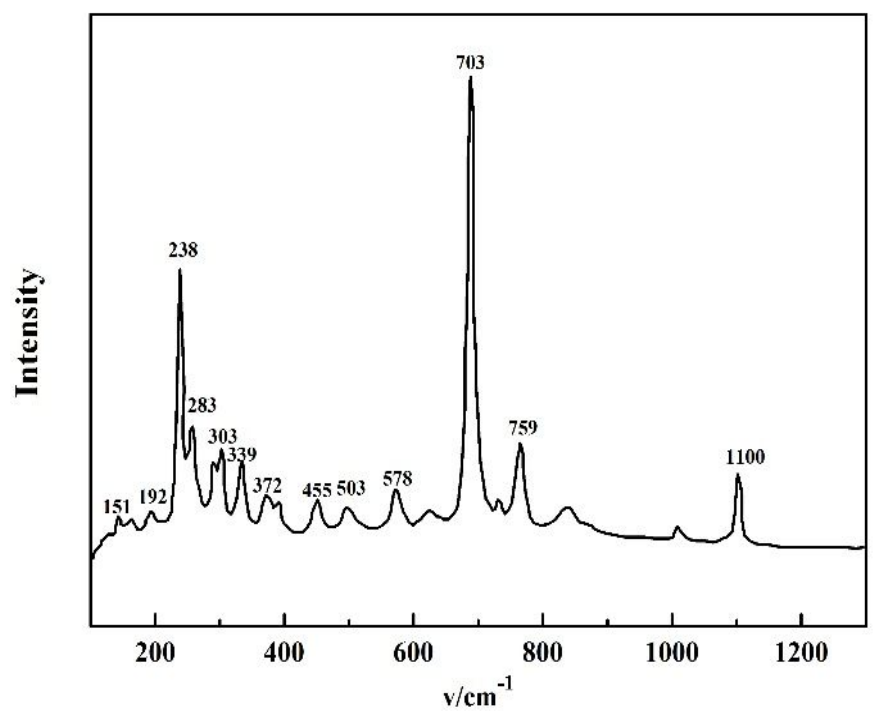


Fig. 8

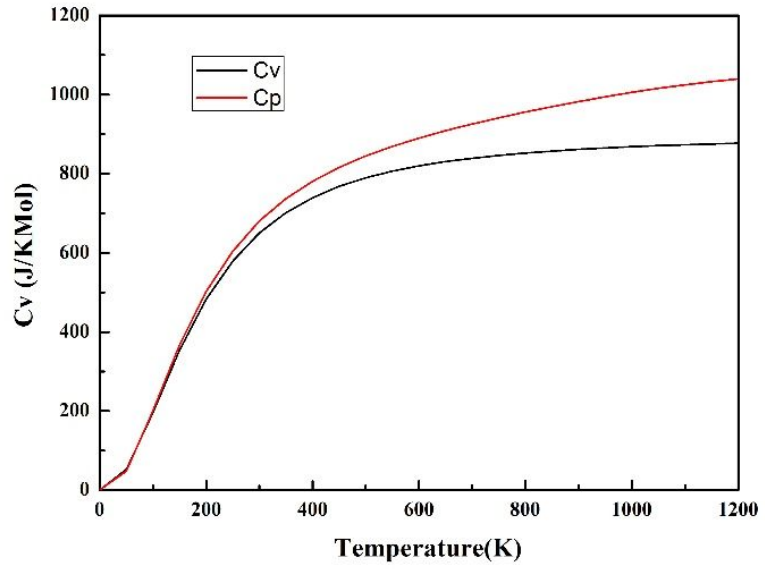


Fig. 9

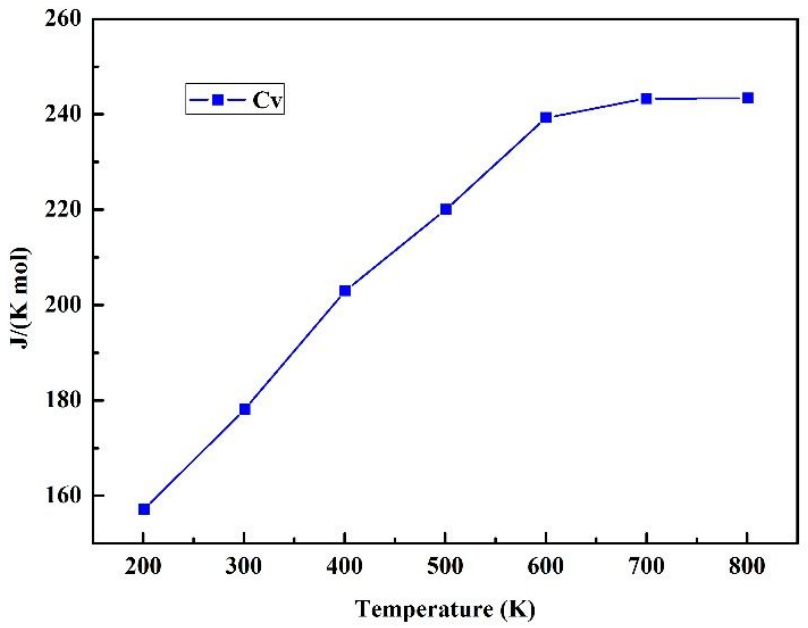


Fig. 10

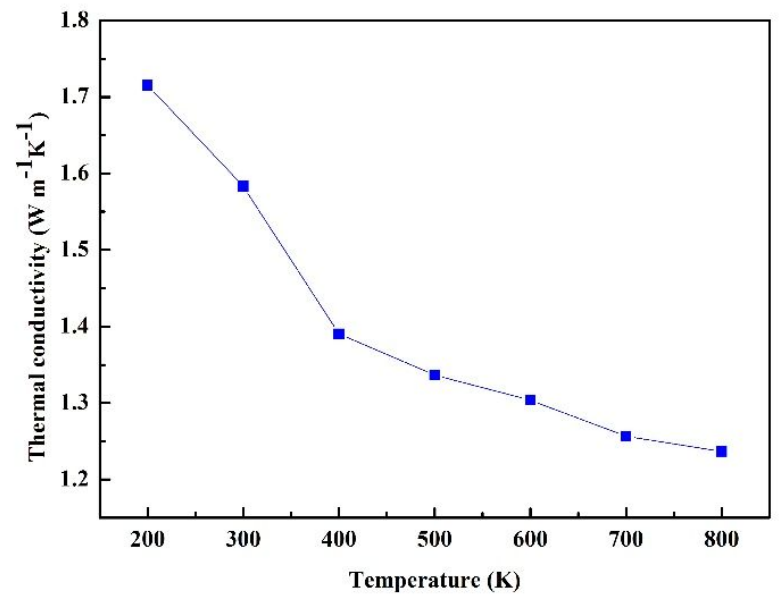


Table 1

\begin{tabular}{|c|c|c|}
\hline & Optimized & Experimental (XRD) \\
\hline $\mathrm{a}(\AA)$ & 7.933 & 7.687 \\
\hline $\mathrm{b}(\AA)$ & 7.739 & 6.501 \\
\hline $\mathrm{c}(\AA)$ & 6.219 & 6.028 \\
\hline
\end{tabular}


Table 2

\begin{tabular}{|c|c|c|c|c|c|}
\hline Raman & calculation & experiment & & calculation & experiment \\
\hline \multirow{8}{*}{$A_{g}$} & 188.71 & 190.31 & \multirow{8}{*}{$\mathrm{B}_{1 \mathrm{~g}}$} & 105.83 & 108.23 \\
\hline & 279.32 & 282.35 & & 201.33 & 203.17 \\
\hline & 357.21 & 357.33 & & 235.21 & 239.21 \\
\hline & 421.11 & 437.71 & & 357.69 & 360.12 \\
\hline & 478.63 & 493.28 & & 408.27 & 409.31 \\
\hline & 539.77 & 578.83 & & 481.26 & 488.23 \\
\hline & 683.68 & 689.72 & & 531.71 & 527.19 \\
\hline & 753.79 & 759.39 & & 703.93 & 719.31 \\
\hline & 198.56 & 200.03 & & 145.61 & 150.76 \\
\hline & 272.92 & 273.17 & & 288.68 & 289.33 \\
\hline \multirow[t]{3}{*}{$B_{2 g}$} & 340.71 & 343.17 & $\mathrm{~B}_{3 \mathrm{~g}}$ & 361.57 & 369.23 \\
\hline & 455.26 & 455.38 & & 450.12 & 450.03 \\
\hline & 508.29 & 513.03 & & 501.53 & 503.28 \\
\hline
\end{tabular}


Toc graphic:
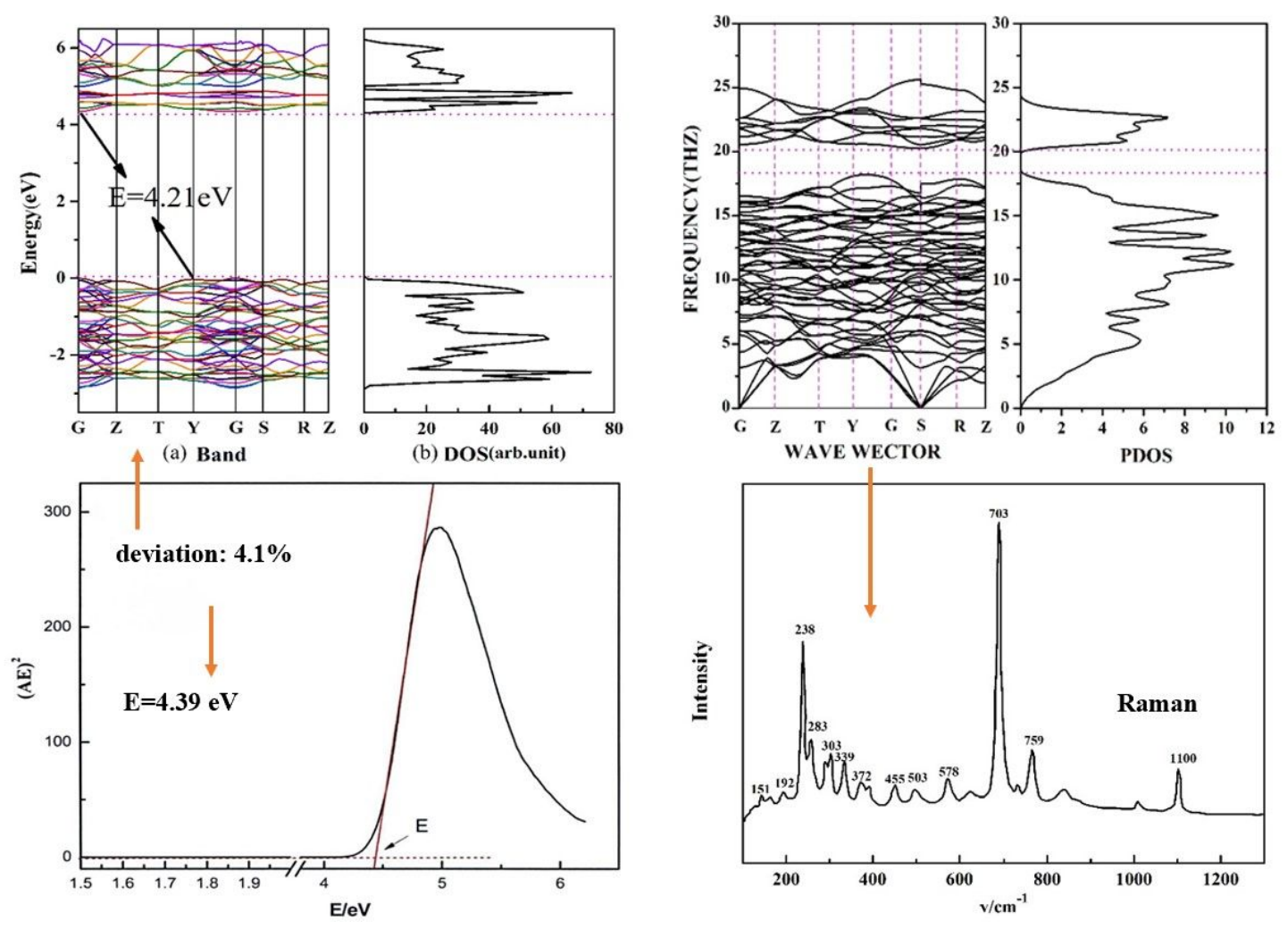